\title{
La abogacía en Cuba: pasado y actualidad a 50 años de la creación de los bufetes colectivos
}

\section{The Law in Cuba: Past and Present 50 Years After the Creation of the Lawyer's Office}

Liuver Camilo Momblanc* y Zoe Cisneros Aldana** http://dx.doi.org/10.21503/lex.v13i16.863

* Profesor auxiliar de la Facultad de Ciencias Sociales y Humanísticas de la Universidad de Guantánamo, Cuba. Licenciado en Derecho y Especialista en Derecho Penal por la Universidad de Oriente en Santiago de Cuba. E-mail: liuver@cug.co.cu

** Profesora de la Facultad de Ciencias Sociales y Humanísticas de la Universidad de Guantánamo, Cuba. Licenciada en Estudios Socioculturales. E-mail: zoe@cug.co.cu 


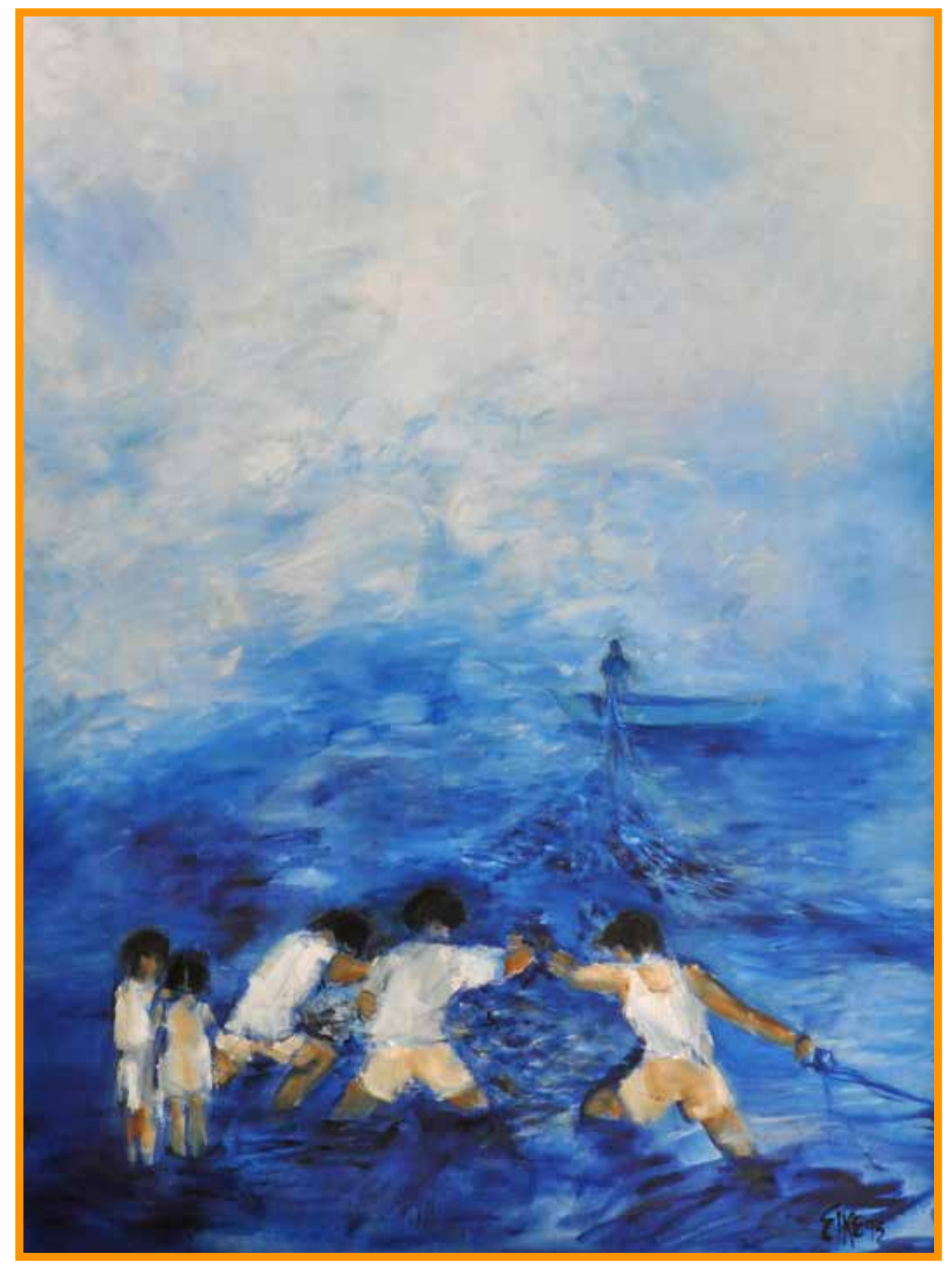

Marina. Colección Lima. Óleo (110x110cm), año1 995. Elke McDonald 


\section{RESUMEN}

En el artículo se realiza una reseña histórica del ejercicio de la abogacía en Cuba. Con tal propósito, los autores sitúan el surgimiento de la figura del abogado en la antigua Grecia y Roma, para luego referirse a España como antecedentes de necesario estudio para la comprensión del nacimiento, desarrollo y consolidación de esta importante profesión en la mayor de las Antillas. Realizan una breve diferenciación de los modelos del ejercicio de la abogacía para resaltar no solo el modelo cubano, sino el elevado ingrediente ético que lo caracteriza y su carácter social, a diferencia de la abogacía liberal. Se detienen en el análisis historiográfico de la profesión en Guantánamo y concluyen con una breve exposición de los retos de los Bufetes Colectivos a 50 años de su constitución. Para ello se auxiliaron de los métodos histórico-lógicos, análisis-síntesis, inductivo-deductivo, hermenéutico, y como técnicas: la entrevista y revisión bibliográfica.

Palabras clave: abogacia en Cuba, abogado, colegios de abogados, Bufetes Colectivos, Organización Nacional de Bufetes Colectivos.

\section{ABSTRACT}

In the article, it is carried out a historical review of the exercise of the legal profession in Cuba. With such a purpose, the authors locate the emergence of the lawyer's figure in the old Greece and Rome, then they refer to Spain like antecedents of necessary study for the understanding of the birth, development and consolidation of this important profession in the bigger than the Antilles. They carry out a brief differentiation of the models of the exercise of the legal profession to not stand out alone the Cuban pattern, but the high ethical ingredient that characterizes it and their social character contrary to the liberal legal profession. They stop in the historiographical analysis of the profession in Guantanamo and they finish with a brief exhibition of the challenges the Lawyer's Offices to 50 years of their constitution. For this, they aided of the methods: historical-logical, analysis-synthesis, inductive-deductive, hermeneutic, and as technical: the interview and bibliographical revision.

Key words: legal profession in Cuba, lawyer, schools of lawyers, Lawyer's Offices, National Organization of Collective Offices. 

La abogacía no se cimienta en la lucidez del ingenio, sino en la rectitud de la conciencia. Esa es la piedra angular; lo demás, con ser muy interesante, tiene caracteres adjetivos y secundarios.

ÁNGel OsSORIO

\section{Una mirada histórica a la abogacía en Cuba}

Sentenció en unas de sus obras de Derecho Penal el catedrático Carlos Fontán Balestra que "para comprender la esencia de una institución jurídica se impone conocer su evolución histórica. El jurista apreciará con más justeza la institución que lo preocupa cuanto más haya penetrado en el campo de la Historia". ' Siguiendo este aforismo, cualquier incursión sobre el ejercicio de la abogacía en Cuba 50 años después de la creación de los Bufetes Colectivos exige, primero que todo, el análisis historiográfico en el país y su institucionalidad. Sin embargo, la génesis de esta actividad trasciende las fronteras de la mayor de las Antillas y como la mayoría de los procesos e instituciones se remonta a la antigua Grecia y a Roma, en las que alcanzó una jerarquía jamás igualada. ${ }^{2}$

En Grecia, los ciudadanos debían asumir la defensa (autodefensa) de sus derechos ante los jueces, proceder que fue confirmado por una disposición en tiempos de Solón (v. 640-558 a.n.e.). Más tarde se comienza a permitir la asistencia a cargo de amigos con habilidades de oratoria a fin de que ayudaran en la exposición de los alegatos. A quienes así operaban se les nombró con el calificativo de synagor y no recibían retribución alguna. Con posterioridad, surgió una figura denominada logógrafo que proporcionaba defensas preparadas para ser leídas por los interesados ante el Tribunal. De esta manera, se fueron haciendo indispensables convirtiéndose con el tiempo en verdaderos abogados consultores y litigantes al servicio de los ciudadanos. ${ }^{3}$

En el caso de Roma existió una diversidad de asistentes jurídicos conocido como: cognitor, procurator, patroni y advocati. Los cognitores y procuratores eran representantes voluntarios vinculados generalmente al procedimiento civil en funciones de mandatario, remontándose sus antecedentes a la primera fase del procedimiento romano, aunque perduró en las fases

\footnotetext{
Carlos Fontán Balestra. Derecho Penal. Introducción y Parte General. 1998, p. 39.

Cfr. Aldo Prieto Morales. Derecho Procesal Penal. Primera Parte. 1976, p. 138.

Cfr. nota 14 de Maya Goite Pierre y Juan Mendoza Díaz. "Los sujetos de la relación jurídico-procesal”. En Temas para el estudio del Derecho Procesal Penal. Primera Parte. La Habana: Editorial Félix Varela, 2002, p. 211.
} 
subsiguientes. Las figuras del oratoro o patroni y la del advocati jugaban un papel distinto al de los anteriores. Su función era la de perorar ante el juez, pero no como representantes de los ciudadanos (quienes podían asistir solos o representados por un cognitor) sino en aras de persuadir al juez mediante su elocuencia. ${ }^{4}$

Como se aprecia, en los primeros tiempos, a pesar de que la función de abogar en juicio no puede ser considerada como una profesión, existieron disposiciones que regulaban el desempeño ante los tribunales y que también se referían al ejercicio de la defensa. Esto, unido al propósito estatal de que se convirtiera en una forma habitual de labor y sustento de quienes lo desempeñaban, demuestra la importancia concedida a esta función y el carácter técnico que desde entonces se le ha atribuido. Si bien en sus inicios fue desempeñada por los propios interesados, familiares, amigos, patronos y pontífices, la propia complejidad y perfeccionamiento de las relaciones sociojurídicas contribuyeron a la exaltación de la figura del "abogado" — con independencia de las distintas denominaciones_-, como garante del derecho a la defensa.

Sin embargo, no se debe obviar que en torno a esta figura desde el comienzo se ha desarrollado un maniqueísmo. Así, por ejemplo, Catón ${ }^{6}$ lo definió como Vir bonus peritus (hombre bueno maestro en el hablar) mientras que Séneca ${ }^{7}$ los estigmatizó como aquellos que "con clamores desentonados venden las palabras en lugar de defender la justicia”. Y quizás en esa misma línea de pensamiento el gran Cicerón ${ }^{8}$ los marcó con el calificativo de "vocingleros rábulas, que creen que la elocuencia consiste en machacar a fuerza de gritos".?

Coincidiendo con Prieto Morales, un estudio del desarrollo histórico de la profesión conduce a una conclusión alejada de la definición de Catón, ${ }^{10}$ quizás más próxima a las ideas

4 Cfr. nota 15. Idem.

5 Además de las ya mencionadas denominaciones no se debe omitir que ya en los tiempos de la culta Roma se diferenciaba el rábula, que era el abogado charlatán que desconocía la ley y la ciencia del Derecho, del leguleyo, que solo conocía la letra de la ley; y el verdadero jurista, el jurisconsulto, versado en la ley y la ciencia del Derecho.

6 Marco Porcio Catón (Roma, 95 a. C. - Útica, 12 de abril de 46 a. C.) fue un político romano. También se le llamó Catón el Joven o Catón de Útica para distinguirlo de su bisabuelo Catón el Viejo o Catón el Censor (234-149 a. C.). Nació en el 95 a. C. en Roma, hijo de Marco Porcio Catón y su esposa Livia Drusa.

7 Marco Anneo Séneca (en latín Marcus Annaeus Seneca), también conocido como Séneca padre, Seneca el Orador, Séneca el Retórico o Seneca el Viejo (54 a. C. - 39) fue un orador romano y escritor, nacido en una familia influyente del orden ecuestre en Corduba. Su praenomen es desconocido, aunque se acepta la conjetura de Rafael de Volterra de llamarlo Marco. Durante una larga estancia en Roma, Séneca acudió a las lecturas de oradores y retóricos famosos, mientras se preparaba para una carrera como abogado. Su orador ideal fue Cicerón, desaprobando la costumbre de su época por las florituras oratorias. Se estima que murió en el año 39.

8 Marco Tulio Cicerón (Arpino, 3 de enero de 106 a. C. Formia - 7 de diciembre de 43 a. C.) fue un jurista, político, filósofo romano. Gran orador y reputado abogado, centró toda su atención en su carrera política. Hoy en día es recordado por sus escritos de carácter humanista, filosófico y político.

9 Cfr. Aldo Prieto Morales. Op. cit. p. 138.

10 Ibidem. 
de Séneca y Cicerón. El hombre bueno no era la regla general en aquellas sociedades en la que reinaba la mentira y la falsedad, herramientas empleadas con frecuencia en el ejercicio de la defensa. Crece el número de abogados y de forma paralela su mala fama provocando que en el Pretorio Romano se limitara su número a ciento cincuenta. ${ }^{11}$

Asimismo, en España fue extraordinario el crecimiento de esta profesión. En la etapa del descubrimiento, conquista y colonización de América, un grupo de escribanos, leguleyos, estafadores, aprovecharon para buscar fortuna y refugio en las llamadas provincias de ultramar. De esta manera, como el Estado y el Derecho, también se importa el ejercicio de la abogacía a Cuba por aquellos inmigrantes indeseables. Para tener una idea de lo que acontecía en torno a esta función y de lo que pudo haber emigrado para la Isla, solo se debe precisar que Carlos IV de España, por Real Orden de 30 de septiembre de 1974, limitó a doscientos los abogados de Madrid. Y Fernando VII se lamentaba de que la multitud de abogados era una de los mayores males del Reino. ${ }^{12}$

Sin embargo, fue precisamente el Rey Fernando VII quien en 1819 ordenó el establecimiento de Colegios de Abogados en La Habana y Puerto Príncipe (actual ciudad de Camagüey); no obstante, determinó la cantidad de colegios que en cada uno de ellos podía figurar e indicó que se regirían por estatutos elaborados por ellos mismos, previa revisión y aprobación de la Real Audiencia. Esta decisión, que como antecedente tuvo en 1799 el traslado hacia Puerto Príncipe de la Real Audiencia de Santo Domingo, constituye el fundamento para que algunos autores afirmen que a finales del siglo XVIII es cuando comienza a gestarse el sector profesional de la abogacía en Cuba, con la creación luego del Colegio de Abogados de Camagüey con Estatutos propios inspirados en el modelo del de Madrid y un número de 24 miembros. No obstante, más tarde se admitieron en sus filas a todos los que se interesaran y cumplieran las rígidas exigencias estatutarias. Por ello, el primer Colegio de Abogados fundado en Cuba no fue el de La Habana de 1852, que por lo demás fue casi automáticamente clausurado por decisión del capitán general de la Isla, fundamentado en razones políticas. ${ }^{13}$ De tal forma que el Gobierno español no permitió su reaparición hasta el año 1879, cuando ya estaban constituidos los de Santiago de Cuba y Trinidad-RemediosSancti Spíritus, desde $1842 .{ }^{14}$

11 Fue entonces cuando se produjo la división entre el abogado jurisconsulto y el abogado defensor (orator). El primero con sus dictámenes brillantemente razonados (responsa prudentum) que dieron lugar a que a algunos se les distinguiera con el privilegio del ius respondendi dicere, o sea que sus dictámenes tenían la fuerza de la norma estatal; y el segundo, como el defensor propiamente dicho ante los tribunales, distinguido por sus informes forenses. Cfr. Aldo Prieto Morales (1976). Ibidem.

12 Cfr. Aldo Prieto Morales. Op. cit. p. 139.

13 Los colegios de abogados fueron centros donde se reunía una intelectualidad permeada por las ideas políticas más liberales de la época, razón por la cual la colonia española siempre vio con recelo a los profesionales del Derecho colegiados para el ejercicio.

14 Cfr. Maya Goite Pierre y Juan Mendoza Díaz. Op. cit. p. 212. 
En septiembre de 1870, España hace extensiva a Cuba su Ley Orgánica del Poder Judicial (LOPJ). En ella se dedicaba un espacio a todo lo relativo a la abogacía, su organización profesional y funcionamiento y continúan los abogados agrupados como estaban en colegios. Así se mantuvieron hasta que en el marco de la primera intervención norteamericana (18991902) se dictó, por el Gobernador Militar el 10 de diciembre de 1900, la Orden Militar No. 500, que disolvió la organización profesional de los abogados cubanos, como medida represiva ante un grupo de protestas realizadas por el Colegio de La Habana. ${ }^{15}$

A partir de entonces no fue requisito la inscripción en ningún Colegio para ejercer la abogacía, derogándose en tal sentido el articulado correspondiente de la LOPJ. Por esta razón, los juzgados y tribunales debieron asumir las funciones que realizaban los Colegios sobre el control de su membresía. Pero el 27 de enero de 1909, durante una segunda intervención militar de los EE.UU, el Gobernador Provisional de la Isla puso en vigor, por Decreto 127, la LOPJ, que derogaba la Ley Orgánica de la Monarquía Española de 15 de septiembre de 1870. Este nuevo cuerpo legal regulaba en el Título XV, denominado "De los abogados y procuradores", todo lo relativo al ejercicio de la abogacía en Cuba.

Mediante este cuerpo legal se instituyeron los Colegios de Abogados como agrupaciones profesionales encargadas de velar por el cumplimiento de los deberes entre los abogados, velar por la eficacia del servicio ante los tribunales, así como por el orden, el decoro, la fraternidad y la disciplina dentro de los colegiados. La facultad disciplinaria sobre la membresía fue una de las más importante atribuciones que se otorgó a los Colegios, como vía para velar por el cabal cumplimiento de los deberes profesionales y ciudadanos, pero se garantizaba la posibilidad de apelar hasta el Tribunal Supremo, en los casos en que el Colegio dispusiera la expulsión de sus filas. ${ }^{16}$

Este requisito de la colegiación obligatoria para el ejercicio de la abogacía se reafirmó luego en la letra del artículo 70 de la Constitución de 1940. En el mismo se establece una reserva de ley para la determinación de la forma de constituirse y financiar dicha organización profesional. Pero solo cuatro años más tarde fue que se da cumplimiento a este mandato constitucional con la promulgación del Decreto No. 781 de 15 de marzo de 1944 y la Ley No.4 de 13 de noviembre del propio año. Y para mayor proveer en julio de 1948, la Asamblea Nacional de Abogados aprobó un Código de Ética para todos los Colegios del país. En este cuerpo legal se definieron las actuaciones que eran consideradas como infracciones de la ética profesional; se regulaban los principios que debían caracterizar las relaciones entre los abogados y entre estos con los tribunales y los clientes; se establecieron las sanciones que podían imponerse por incumplimiento de la ética profesional y el procedimiento para su

15 Cfr. Maya Goite Pierre y Juan Mendoza Díaz. Ibídem. p. 212-213. Aldo Prieto Morales. Op. cit. p. 140.

16 Maya Goite Pierre y Juan Mendoza Díaz. Op. cit. p. 213. 
determinación. Ciclo este que se cierra en marzo de 1949 cuando la Junta de Gobierno de Abogados de La Habana acordó sus Estatutos, los que fueron aprobados por la Sala de Gobierno del Tribunal Supremo en mayo del propio año.

Pero, ¿cuál era la situación y visión social de este importante sector durante la seudorrepública? Como ya se expresaba supra al referirse al maniqueísmo que engloba la profesión, se atribuye a la burguesía el hecho de que esta función descendiera en muchos casos a la vileza y que fuera menospreciada por el pueblo. Solo unos pocos, por su habilidad y técnica o la protección económica familiar, constituían una aristocracia de la profesión mientras la mayoría se encontraban obligados a hacer milagros para ganar el diario sustento. Así, la dura realidad de esta mayoría fue descrita con claridad por Fidel Castro al expresar que:

Los abogados eran explotados, porque salian de la universidady tenian que parar en un bufete; ese bufete ya lo controlaba un grupo de magnates [...], que lo controlaba todo; tenían las relaciones con todas las empresas, monopolios, bancos, gente rica, y entonces los abogados recién graduados tenian que ir a parar a esos bufetes.

En consecuencia, sin perjuicio de las lógicas excepciones, el concepto que se tenía de los abogados en la sociedad cubana en aquella etapa ${ }^{17}$ burguesa era el de un sujeto carente de valores morales. Esta situación condujo a Ángel Osorio realizar la siguiente reflexión en El Alma de la Toga:

Suele sostenerse que la condición predominante de la abogacía es el ingenio. El muchacho listo es la más común simiente de abogado, porque se presume que su misión es defender con igual desenfado el pro que el contra y, a fuerza de agilidad mental, hacer ver lo blanco negro. Si la abogacía fuera eso, había menester que pudiera igualarla en vileza: incendiar, falsificar, robar y asesinar, serán pecadillos venales si se les compara con aquel encanallamiento; la prostitución pública resultaría sublimada en el parangón, pues al cabo, la mujer que vende su cuerpo puede ampararse en la protesta de su alma mientras que el abogado vendería el alma para nutrir el cuerpo.

Con el triunfo revolucionario del 1 ro de Enero de 1959, que derrocó el régimen dictatorial imperante, se produjeron profundos cambios no solo en las estructuras de gobierno, sino en todo el orden social establecido, del cual la abogacía es parte importante. En consecuencia, el paulatino proceso de radicalización de las posiciones en el seno de la sociedad cubana tuvo su lógico reflejo en la organización, funcionamiento y reconocimiento del papel social del abogado.

17 Ángel Ossorio. El ángel de la toga. Buenos Aires; Argentina: Losada, 1942. 
Así, en el año1962, en Asamblea General de los colegios, se aprobó un nuevo Estatuto del colegio de Abogados de La Habana que radicalizaba las posiciones desde el punto de vista político y derogó el que había estado vigente desde el año 1949. Dos años más tarde, el 21 de diciembre de 1964, la Junta de Gobierno de este colegio propuso al Ministro de Justicia la creación de una agrupación de abogados que se denominaría Bufetes Colectivos y que funcionaría conforme a bases propuestas por la propia Junta. Con ello se pretendía la creación de una opción que resultara verdaderamente popular, mediante la cual todo ciudadano pudiera acceder a la justicia, en base a tarifas de cobros de los asuntos sustancialmente disminuidas con relación a las que se pagaban a los letrados que privadamente ejercían la profesión.

De esta forma, el 22 de enero del año 1965, el Ministro de Justicia, por Resolución No. 18, aprobó la creación del primer Bufete Colectivo en la capital del país, que estaría sujeto a la jurisdicción del Colegio de La Habana, bajo la orientación y supervisión del Ministro de Justicia. Fue esta la fecha oficial de la constitución en Cuba de tal organización integrada por abogados que renunciaron al ejercicio privado de la profesión. Fue así que la función del abogado dejó de ser privada y pasa a ser lo que se conoce internacionalmente como Abogacía de Estado. "Atrás quedó, con el hundimiento de la sociedad burguesa, el abogado dolosamente mendaz, obediente solo al interés de su representado y, principalmente, a su propio interés económico, $[\ldots] "{ }^{18}$

El Consejo de Ministros del Gobierno Revolucionario dictó el 25 de abril de 1966 la Ley No. 1189, mediante la cual se dispuso la inscripción de los abogados en el Registro del Ministerio de Justicia, como requisito para el ejercicio profesional, eliminando el control de la colegiatura hasta esa fecha en poder de los Colegios. Pero hasta el año 1974 coexistieron en el país ambas modalidades de ejercicio profesional: de una parte los abogados que se desempeñaban privadamente y de la otra los Bufetes Colectivos del Ministerio de Justicia, con un enfoque más social de su función y con tarifas de cobro de los servicios sustancialmente inferiores.

En el año 1973, el Consejo de Ministros dictó la ley 1250 "Ley de Organización del Sistema Judicial", al que se enmarcaba en lo que se conoció como "proceso de institucionalización" (LOSJ), período en el que fueron promulgadas las principales Leyes del Estado. Esta específicamente eliminó por completo en Cuba el ejercicio privado de la abogacía e hizo nacer una nueva y peculiar institución en el sistema de justicia del país, que si bien seguía conservando el nombre de Bufetes Colectivos, se apartaba de la concepción organizativa y estructural de la existente hasta ese momento. ${ }^{19}$

18 Aldo Prieto Morales. Op. cit. p. 137.

19 En su artículo 171 dispuso que la comparecencia ante los tribunales en calidad de abogado requería la pertenencia del letrado a un bufete colectivo. Con su entrada en vigor se incorporaron a las unidades de bufetes colectivos 254 juristas, y 
La nueva Organización era definida por la Ley como una "institución autónoma nacional, de interés social”, regida por un Reglamento interno, el que debía ser aprobado por el Tribunal Supremo. Se establecieron los requisitos generales para poder pertenecer a los Bufetes Colectivos, función que era incompatible con el desempeño de otras responsabilidades judiciales, fiscales o de cargos públicos que implicaran autoridad. Regulación esta que estuvo vigente durante esta década y los primeros años de la década de los 80 .

\section{La abogacía en Cuba a la luz del Decreto Ley No. 81}

La Reorganización de los Bufetes Colectivos propició una mejoría en la composición de los abogados, con la incorporación a esta profesión de jóvenes juristas que, con una nueva concepción de su papel, contribuyen a elevar la calidad de los servicios jurídicos a la población.

Informe Central al III Congreso del PCC

El 8 de junio de 1984, el Consejo de Estado promulgó el Decreto Ley No. 81 "Sobre el ejercicio de la Abogacía ${ }^{20}$ y la Organización Nacional de Bufetes Colectivos". ${ }^{21}$ Con este cuerpo legal nace en Cuba una nueva Organización para la abogacía (Organización Nacional de Bufetes Colectivos) que se define como una "entidad autónoma nacional de interés social y carácter profesional, con personalidad jurídica y patrimonio propio, integrada voluntariamente por juristas". ${ }^{22}$

De esta manera, conforme expresa Adolfo Rodríguez Fernández-Rubio, ${ }^{23}$ de las formas tradicionales de organización para el ejercicio de la abogacía se sigue en Cuba la colectiva en contraste con la liberal y la prusiana o estatalizada. Sin dudas, de las tres, la de mayor carácter popular pues garantiza el acceso a la justicia, así como la independencia de los poderes públicos. Lo primero, porque se aplica según el tipo de asunto y su "complejidad" un sistema de tarifas, iguales y económicas en aras de que los servicios jurídicos puedan resultar accesibles a los clientes e incluso en algunos casos puede rebajarse o eximirse de su pago en

ya al finalizar 1978 la cifra de abogados pertenecientes a los bufetes colectivos ascendía a 600, que prestaban sus servicios en 61 unidades.

20 El primer artículo de esta normativa reza que "El ejercicio de la abogacía consiste en evacuar consultas y dirigir, representar y defender los derechos de una persona natural o jurídica ante los tribunales de justicia, los órganos de arbitraje y los organismos administrativos en el territorio nacional, así como ante los órganos, organismos y organizaciones extranjeras o internacionales".

21 El Reglamento de esta disposición normativa se dictó el 18 de diciembre del propio año, a través de la Resolución 142 del Ministro de Justicia.

22 Cfr. artículo 5 del Decreto Ley No.81 de 8 de junio de 1984.

23 Adolfo Rodríguez Fernández-Rubio [Director Provincial de Bufetes Colectivos]. En entrevista efectuada por Liuver Camilo Momblanc. Guantánamo, 26 de diciembre de 2014 a las 8:30 am. 
correspondencia con sus ingresos. En cada municipio existe una unidad del Bufete y toda persona podrá designar al abogado de su elección así como a sus sustitutos eventuales con el único requisito de la firma del contrato de servicios jurídicos. ${ }^{24}$ Otro aspecto a resaltar es que las consultas que se brindan sobre temas legales son también gratuitas, así como se prevé la forma de resarcir monetariamente a los clientes que resulten perjudicados por la prestación deficiente de un servicio profesional.

La independencia, por su parte, está basada en que el abogado en su actuar solo debe obediencia a la ley y a lo normado por la Organización; disfruta de todos los derechos y garantías legales para exponer sus alegatos en relación con el derecho que defienda, pero siempre contribuyendo a la realización de la justicia, mediante la observancia y el fortalecimiento de la legalidad socialista, así como a la educación social de sus representados y de todos los ciudadanos. ${ }^{25}$

Contrario sensu, la abogacía liberal se rige por el imperio del valor, convirtiéndose en un negocio donde los grandes bufetes aplastan a los más pequeños, mientras que la estatalizada o prusiana es objeto de asaz cuestionamiento porque sus actores responden al Estado que los organiza, remunera y controla, provocando esto que los clientes pierdan la confianza en un servicio que se les presta bajo estas condiciones.

Como se aprecia, a partir del Decreto Ley quedó proscrito el ejercicio privado, autónomo o por cuenta propia ${ }^{26}$ de la abogacía en Cuba como es usual en el extranjero. Por ello, esta disposición normativa atribuye la categoría de Abogado a quienes ejercen la abogacía habitualmente dentro de la Organización, pero para ejercerla se necesita estar capacitado por título expedido por centro de educación superior en el país o en el extranjero previo su reconocimiento o convalidación, y ser admitido por la Organización. No obstante, de manera excepcional el Ministro de Justicia puede autorizar a que determinados juristas que se desempeñan en otras funciones ejerzan temporalmente como abogados, y también con

24 Cfr. artículo 20 del Decreto Ley No. 81 de 8 de junio de 1984 y los artículos siguientes artículos del Reglamento: Artículo 48: Los Directores de las unidades de Bufetes Colectivos son los facultados para autorizar la rebaja o exención de pago por los servicios jurídicos que se prestan por los abogados adscriptos a las unidades que dirigen. A ese efecto deben exigir al usuario que pruebe el monto de sus ingresos. La Junta Directiva Nacional debe tener en cuenta los criterios de los órganos competentes de la asistencia social que rijan al respecto, a los efectos de regular las pruebas de los ingresos económicos de los usuarios que soliciten la rebaja o exención del pago.

Artículo: Cuando la persona solicitante del servicio jurídico pueda lesionar sensiblemente su economía familiar y por las características y composición del núcleo resulte recomendable, puede reducirse la tarifa hasta un 50\%. La exención del pago se brinda cuando la persona solicitante del servicio sea considerada con ingresos insuficientes, según los criterios que en tal sentido estén establecidos por el órgano competente de la Asistencia Social.

25 Cfr. artículo 2 del Decreto Ley No. 81 de 8 de junio de 1984.

26 Si bien se deduce del texto del Decreto Ley 81, lo ratifica el hecho de no estar incluida la abogacía entre las actividades que autoriza el actual Reglamento del ejercicio del trabajo por cuenta propia: Resolución 42 de 2013 del Ministerio de Trabajo y Seguridad Social, publicada en la Gaceta Oficial No. 27, Edición Extraordinaria, de 26 de septiembre de 2013. 
carácter excepcional pero sin necesidad de esta autorización previa lo pueden hacer los juristas vinculados laboralmente a las sociedades civiles de servicios reconocidas por la legislación vigente; ${ }^{27}$ los que asuman la representación o dirección de asuntos relacionados con sus propios derechos, con los de su cónyuge o con los de sus parientes hasta el cuarto grado de consanguinidad o segundo de afinidad; los juristas de organismos, cuando comparezcan en representación de los intereses de su entidad o los dirigentes de estas, sobre hechos relativos a las funciones de su cargo, o sea, no pueden tratarse de asuntos particulares; y los docentes de las Facultades de Derecho con el objetivo de vincularse a la práctica profesional. ${ }^{28}$

Los abogados de la Organización no tienen la condición de empleados sino la categoría de miembros de esta asociación profesional. La relación laboral abogado-ONBC se establece a partir de la admisión a la Organización que concede la Junta Directiva Nacional, momento en el que le son aplicables las disposiciones laborales comunes, con excepción del régimen disciplinario al que se adicionan un conjunto importante de requerimientos éticos. ${ }^{29} \mathrm{En}$ consecuencia, es necesario reunir condiciones morales adecuadas, no haber sido sancionado por delito intencional que lo haga desmerecer en el concepto público, ni hallarse sujeto a proceso penal por delito de esa naturaleza. ${ }^{30}$

Del régimen laboral ordinario reciben todos los beneficios que en él se establecen, por ejemplo, en materia de protección e higiene del trabajo, duración de la jornada laboral, el derecho a la retribución y al descanso, y el régimen de seguridad social.

La investigación disciplinaria contra algún abogado puede iniciarse en virtud de violación de sus obligaciones profesionales o de la ética. ${ }^{31}$ En su tramitación se conforma un sumario en el que el procesado debe realizar los descargos que considere oportunos y aportar las pruebas de que intenta valerse.

Las medidas disciplinarias que se le pueden imponer van desde la amonestación y la multa, hasta la separación de las filas de la Institución. Las mismas pueden ser recurridas en Alzada ante la Junta Directiva, sin ulterior reclamación, excepto en los casos en que se disponga la separación definitiva, en que cabrá el Recurso de Queja ante el Ministro de

27 Constituyen las creadas para la representación y asesoramiento de asociaciones económicas donde está presente capital extranjero y otros asuntos de naturaleza afín, que se ventilan tanto en Cuba como en el extranjero (v.gr. Consultores Asociados S. A, CONAS, Consultoría Jurídica Internacional; etc.).

28 Cfr. artículos 3 y 4 del Decreto Ley No. 81 de 8 de junio de 1984.

29 Las particularidades del régimen disciplinario en comparación con los del resto de los juristas (jueces, fiscales, etc.) se corresponde con las exigencias que establecidas en los Principios Básicos sobre la función de los Abogados, aprobadas en el VIII Congreso de Naciones Unidas sobre prevención del delito y tratamiento del Delincuente celebrado en La Habana del 27 de Agosto al 7 de Septiembre de 1990.

30 Cfr. artículos 16 y 17 del Decreto Ley No. 81 de 8 de junio de 1984.

31 Cfr. artículo 24 del Decreto Ley No. 81 de 8 de junio de 1984. 
Justicia, quien tiene la facultad de reponer al reclamante en la condición de miembro de la Institución y disponer que se le indemnice por los daños y perjuicios sufridos por la medida impuesta. ${ }^{32}$

La Organización de Bufetes Colectivos también tiene entre sus tareas la de recibir y entrenar a los juristas recién egresados de las Facultades de Derecho, que son ubicados en Bufetes por un período de tres años para que se adiestren; culminado ese tiempo, pueden solicitar el ingreso como miembros de la Organización o pasar a laborar a otros organismos. También pueden ejercer como abogados los licenciados en Derecho que aspiren a ingresar a la Organización provenientes de otras entidades, en calidad de abogados adjuntos durante el período de un año, hasta que se apruebe o no su incorporación plena y definitiva, previo cumplimiento de las exigencias ya mencionadas y recientemente, a lo expresado se adiciona para todos el requisito de aprobar un examen académico. ${ }^{33}$

Desde el punto de vista estructural, el Decreto Ley definió la existencia de una Asamblea General como el órgano superior de la Organización, integrada por delegados electos en los distintos Bufetes del país, por un período de cinco años. Dicha Asamblea se reúne una vez al año y tiene entre sus funciones, además de la elección de la Junta Directiva, evaluar y adoptar decisiones sobre los informes de rendición de cuentas de la Junta, aprobar los lineamientos anuales de trabajo y el presupuesto de la institución, así como la de rehabilitar como miembros de la organización a los abogados que hayan sido separados en virtud de medida disciplinaria. ${ }^{34}$ La Junta Directiva Nacional, integrada por siete miembros (Presidente, Vicepresidente Primero, Vicepresidente, Tesorero, Vicetesorero, Secretario y Vicesecretario), es la encargada de dirigir el trabajo de la institución entre cada periodo de sesiones de la Asamblea General. ${ }^{35}$

Además de las diferentes unidades de bufetes en cada provincia y municipio del país, la Ley otorga la posibilidad de crear Bufetes Especializados para la atención a determinados asuntos de una rama o especialidad del Derecho; este es el caso del Bufete de Casación, radicado en La Habana y que tiene por tarea atender ante el Tribunal Supremo los trámites de personerías y vista de los recursos interpuestos por los abogados que radican en bufetes distantes de la capital del país.

En la actualidad, la Organización Nacional de Bufetes Colectivos cuenta con 4046 trabajadores, de los que 1986 son miembros plenos, y 255 ejercen como abogados en calidad de egresados, para un total de 2241 letrados en ejercicio, que representa un 55,38\% del

32 Cfr. artículos 28-30 del Decreto Ley No. 81 de 8 de junio de 1984.

33 Cfr. Acuerdo 895 de 2012 de la Junta Directiva Nacional (Norma 3 del Cap. 1 del Manual de Normas y Procedimientos).

34 Cfr. artículos 7-9 del Decreto Ley No. 81 de 8 de junio de 1984.

35 Cfr. artículos 10-12 del Decreto Ley No. 81 de 8 de junio de 1984. 
total de su fuerza de trabajo, y de los que un $93,5 \%$ se encuentra efectivamente vinculado al ejercicio de la profesión. O sea que aproximadamente 2095 licenciados en Derecho se desempeñan como abogados en todo el país y el servicio se presta en 180 bufetes agrupados en 72 unidades territoriales. ${ }^{36}$ Además se defiende la idea de que la existencia de la Organización constituye la premisa de la tutela legal del ejercicio de la abogacía, y es en sí misma el principal mecanismo de protección de los abogados.

\section{La abogacía en Guantánamo: pasado y actualidad}

Antes del triunfo revolucionario del 1 ro de Enero de 1959, solo existían en Guantánamo algunos abogados que ejercían la profesión de manera privada cumpliendo con el requisito de la colegiación en aquellos periodos en que se exigió. ${ }^{37} \mathrm{Nada}$ de particular se advierte en esa época que merezca ser destacado del proceso histórico narrado en el primer epígrafe.

Así fue, hasta que en 1967 cuando ya habían transcurridos dos años de la creación del primer Bufete Colectivo en La Habana, se estableció el de Guantánamo en el inmueble marcado por el número 1058 en la calle Los Maceos entre Donato Mármol y Bernabé Varona. Como había acontecido en aquella experiencia, también este lo integraron abogados que renunciaron al ejercicio privado de la profesión. En aquel momento fundacional solo fueron dos los trabajadores de esta nueva institución: el Dr. Fidel S. Silot Sanregré, quien se desempeñó como Abogado y Director del Bufete, y René Garriga Fuertes (ya fallecido), como técnico auxiliar. ${ }^{38}$

Esta Institución prestó a la población diferentes servicios que trascendían el de la representación o asistencia técnica, pero que por las características de la localidad fueron autorizados por el Ministro de Justicia hasta que con el desarrollo de la institucionalidad en el país fueron reorientados a otros organismos del sector jurídico. Fueron estos los servicios de Notaría, Archivo de Protocolos y Registro de la Propiedad desde Guantánamo hasta Baracoa, entre otros.

Transcurridos algunos años, se produce un aumento del personal del Bufete con la incorporación de otros abogados como el Dr. Antonio Millet Navarro y la colaboración en los trabajos mecanográficos de Ibrain Rodiles, quien ya se desempeñaba como Secretario de la Sala Civil. Y cuando Fidel Silot es designado por el Partido para el cumplimiento de tareas

36 Los datos provienen del Informe de la Junta Directiva Nacional a la Asamblea General, celebrada el 20 y 21 de marzo de 2014, La Habana. Citados por Alida Cagigas Rodríguez y Pavel Peterssen Padrón. Aproximación a la responsabilidad de los abogados en el ejercicio de la profesión y sus mecanismos de protección legal. Disponible en: CD del Congreso Abogacía 2014.

37 Ver ut supra, epígrafe I.

38 Información tomada del documento inédito intitulado "Los Bufetes Colectivos en la historia", elaborado por el compañero Llorente, actual Director de Cuadros de la Dirección Provincial de Bufetes Colectivos en Guantánamo. 
en la entonces Región Guantánamo, se produce cambio en la dirección que fue asumida por el Dr. Adalberto Parúa y luego por el Dr. Enio Camué. ${ }^{39}$

En 1970 se fundó el Bufete de Baracoa con un solo abogado, el Dr. Idelfonso Pellicier, contándose entonces con dos unidades de Bufetes en la Región. Y en la primera mitad de esta década, el Bufete de Guantánamo fue trasladado para el inmueble que hasta hoy ocupa la Unidad de Bufetes Colectivos No. 1, sito en Martí esquina Crombet No. 904, de mejores condiciones de infraestructura y mayor amplitud. Pero no fue sino hasta el año 1974, a tenor del Decreto Ley No. 81 del Ministerio de Justicia, que se crea la Organización Nacional de Bufetes Colectivos como

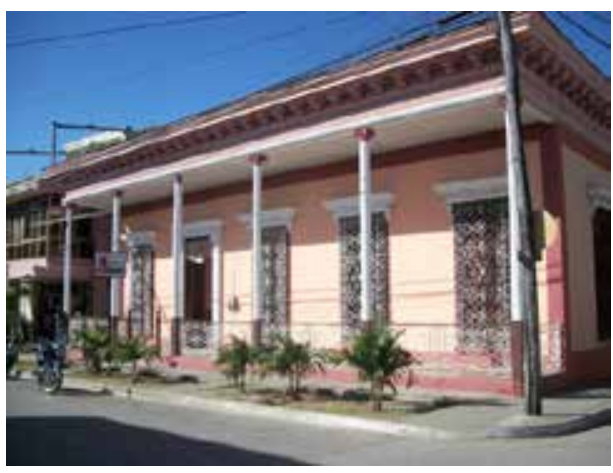

Ilustración 1. Unidad de Bufetes Colectivos No. 1 hoy se conoce y ya se expuso en el segundo epígrafe de este trabajo. Una organización con carácter autónomo, de interés profesional y patrimonio propio, suprimiéndose por completo el ejercicio privado de la abogacía en el país. De este modo los abogados que se negaron a ingresar a la Organización tuvieron que dejar de ejercer la profesión. ${ }^{40}$

Con la formación de nuevos juristas y la admisión de un importante número de ellos en la Organización para dar satisfacción a la demanda de la población y las personas jurídicas, fue necesaria la adquisición de nuevos locales. Por ello, a finales de la década de los 90 se compró el inmueble ubicado en la Calle Martí No. 665 entre Paseo y Narciso López, denominado Unidad de Bufetes Colectivos No. 2, donde radica al mismo tiempo la Filial del BES.

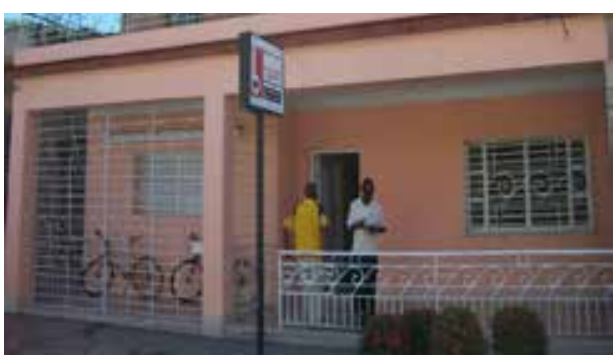

Ilustración 2. Unidad de Bufetes Colectivos No. 2.

También en ese periodo se trasladó la Unidad de Bufete Colectivos de Baracoa para un nuevo local sito en Calle Martí No. 218 en ese municipio.

Es así que en la actualidad la provincia cuenta con tres unidades de Bufetes Colectivos. La histórica y ya tradicional Unidad No. 1, que a su vez tiene cuatro extensiones en

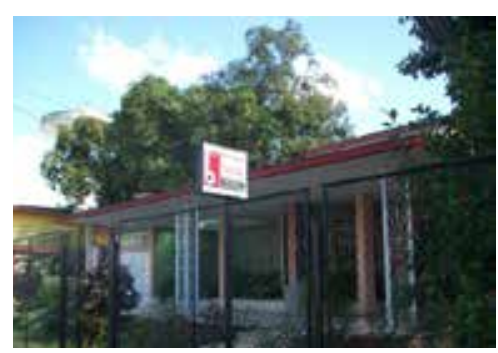

Ilustración 3. Dirección Provincial de Bufetes Colectivos Guantánamo.

39 Cfr. documento inédito intitulado "Los Bufetes Colectivos en la historia”, elaborado por el compañero Llorente, Director de Cuadros de la Dirección Provincial de Bufetes Colectivos en Guantánamo.

40 Vid. ut supra, epígrafe II. 
los municipios de Manuel Tames, Niceto Pérez, Yateras y el Salvador, con un total de 31 abogados. La unidad No. 2, que incluye el servicio por extensión en el municipio Caimanera y San A. del Sur con 17 abogados. También la unidad de Baracoa que atiende los municipios de Imías y Maisí con 14 abogados. A lo que se une la Dirección Provincial ubicada en la Calle 13 de Junio entre 14 y 15 Sur, en el Reparto Caribe de la Ciudad de Guantánamo. Todo lo que suma un total de 124 trabajadores en general de los que 66 son abogados. De ellos, 23 ostentan la categoría académica de Máster en Ciencias o Especialistas de Postgrados, evidencia del alto nivel técnico y científico de estos profesionales de la toga.

Ahora bien, todas las unidades prestan servicios nacionales e internacionales encaminados a la asesoría, representación y defensa de los derechos de las personas naturales y jurídicas nacionales y extranjeras en todas las materias del Derecho con facultades para actuar ante los tribunales de justicia, órganos administrativos en el territorio nacional y ante órganos, organismos y organizaciones extranjeras o internacionales, así como la tramitación de documentos y gestiones ante instancias administrativas, consulta gratuita, y servicios especializados del BES y BEC. ${ }^{41}$

Como misión, la Organización tiene la de prestar servicios jurídicos con calidad a personas naturales y jurídicas, contando con profesionales calificados en todas las ramas del Derecho, con una cultura intelectual y ética, así como con una eficacia en su gestión reconocida por los clientes y toda la sociedad. Y como visión la de lograr:

- La prestación de un servicio ético y eficaz, cuya calidad resulte constatable mediante sistemas fiables.

- Consolidar una fuerza laboral integrada por miembros y trabajadores que comparten objetivos y valores comunes, y luchan por su realización en un clima organizacional propicio.

- Participación activa en las actividades fundamentales de la vida y cultura jurídica de la nación, con reconocimiento del aporte intelectual de sus miembros.

- Obtener el $80 \%$ de especialización de los abogados miembros, así como la totalidad de los técnicos con progresión profesional demostrada.

- Mantenerse como una institución económicamente sustentable.

Finalmente, resultado de las diferentes entrevistas realizadas se pudo constatar que en términos generales el pueblo tiene una gran satisfacción de la abogacía en Guantánamo. Una provincia particularizada por las características de su territorio y que a pesar de ello ha

${ }^{41}$ Cfr. documento inédito intitulado "Los Bufetes Colectivos en la historia". 
logrado asegurar la presencia del servicio de abogacía en lugares intrincados, como Maisí y Yateras. Así, para orgullo nuestro, sostienen dos de los abogados entrevistados, ${ }^{42}$ Guantánamo es una provincia cuya membresía de abogados ha sido evaluada satisfactoriamente también por la Dirección Nacional de la Organización por los estándares de calidad alcanzados en la prestación del servicio y la seriedad en la prestación del servicio. Una abogacía donde cada cual se conserva en los valores del saber jurídico, de la honradez y de la humildad con que se debe asumir ese rol cuando se le coloca en la mano el encargo del servicio jurídico.

\section{Cincuenta años del Bufete Colectivo en Cuba: retos y perspectivas}

La llamada "sociedad moderna" que nos ha tocado vivir, marcada por una convergencia tecnológica que experimenta la electrónica, la informática y las telecomunicaciones, tiene su mayor exponente en el vertiginoso crecimiento alcanzado por Internet, haciendo la vida cotidiana mucho más rápida y truculenta. Nos movemos en un entorno social donde la información y los conocimientos son el elemento definitorio de las relaciones entre los individuos y naciones. Se dinamiza y complejiza la sociedad. La rapidez y el caudal de la recepción de las informaciones aumentan de una manera que no está en armonía con el ritmo del pensamiento y de la comprensión de la naturaleza humana. La actual capacidad de innovación tecnológica conlleva a una profunda transformación de las personas, organizaciones y culturas que parece ir por delante de la valoración de sus riesgos y repercusiones sociales.

En este contexto suele apreciarse un incremento y complejidad de las relaciones sociales que trascienden con mayor velocidad las fronteras nacionales. Se generan nuevas relaciones civiles, contractuales, laborales, mercantiles, económicas, de propiedad intelectual, etc., y con ellas nuevos conflictos con repercusión jurídica cuya solución requiere del asesoramiento técnico-profesional, de la contratación de los servicios de un abogado. En consecuencia, la sociedad cubana actual demanda de la Organización Nacional de Bufetes Colectivos la prestación de un servicio de excelencia a tono con los cambios que se producen en aras de la actualización del modelo económico bajo los principios del socialismo. Por ello, la necesidad de reflexionar sobre los principales retos y perspectivas de la abogacía en Cuba transcurrido medio siglo de su constitución.

Sin dudas, los conflictos que hoy se suscitan, además de diferentes suelen ser más ininteligibles porque han confluido en ellos los vientos de la época moderna. Esto exige cada vez más de un abogado integral, con una preparación no solo técnica sino política y de una cultura general que le permita dar solución a los problemas sociojurídicos sometidos a su consideración.

42 Adolfo Rodríguez Fernández Rubio. Op. cit. \& Rafael Arrúe Caraballo [abogado con 24 años en el ejercicio profesional, fue director de la Unidad de Bufete Colectivo No.2]. Entrevista efectuada por Liuver Camilo Momblanc. Guantánamo, 30 de diciembre de 2014 a las 10:30 a. m. 
Los casos en tramitación son de mayor envergadura. Por citar algunos ejemplos: en lo penal, los modus operandi son más complejos, mayor la cantidad de sujetos intervinientes en la ejecución de los ilícitos... Las malversaciones ya no son las de diez años atrás en sus formas comisivas y las cuantías son exorbitantes. En lo civil y administrativo, los conflictos son graves porque en gran medida ya se han agotado otras vías y el contenido patrimonial también es elevado. En materia de familia, la emigración y las misiones internacionalistas han traído secuelas bien marcadas. La guarda y cuidado del menor en defecto de uno de los padres que está fuera del país y el reclamo de los abuelos por asumirla y no contar con el respaldo legal para ello a pesar de que el padre presente nunca se ha preocupado por el infante, resulta uno de los conflictos más recurrentes.

La aquiescencia de la homosexualidad como estado de orientación sexual también genera un sistema de contradicciones con soluciones en el campo de la bioética, pero no aún en el jurídico, al menos en el caso cubano, al no poseer soporte legal como derivación de la repercusión social que implica.

Como se aprecia, la necesidad de una constante autopreparación y actualización por parte del abogado parte de las materias tradicionales del Derecho y a la vez la trasciende. Hoy este debe profundizar en todo lo referido a las cooperativas no agropecuarias que tienen una fuerza enorme en la sociedad cubana actual, el sector empresarial, el Derecho Financiero y Económico, donde realmente los retos son mayores a partir de todas las modificaciones que se han establecido, teniendo como base los Lineamientos de la Política Económica y Social del Partido y la Revolución. ${ }^{43}$

En este entorno, es lógico que el cliente tenga otras peculiaridades que las de antaño. A pesar de que existen autores que los clasifican según diferentes posturas, en general hoy se aprecia un cliente que conoce, revisa internet, accede a informaciones de toda índole, debate Derecho e incluso sugiere soluciones a su caso. Esto exige del abogado mayor preparación para cumplir su rol sin faltar a la ética, lo cual logrará si lo trata con el debido respeto y convence a partir de mostrar que posee los conocimientos necesarios. Por ello, continúa siendo un reto para este profesional, conforme reza el artículo 2 del Decreto Ley No. 81, mantenerse actualizado sobre la legislación vigente y sus modificaciones y dispuesto a perfeccionar permanentemente sus conocimientos del Derecho.

Así, queda al descubierto, como sentencia Adolfo Rodríguez Fernández-Rubio, ${ }^{44}$ que a 50 años de la creación de la abogacía en Cuba y 30 de la constitución de la ONBC en una

43 Kirenia Rodríguez Portuondo [Directora de la Unidad de Bufete Colectivo No. 1]. Entrevista efectuada por Liuver Camilo Momblanc. Guantánamo, 25 de diciembre a las 10:00 am.

44 Ibidem. 
sociedad cambiante, también hay que repensar el entramado socioeconómico que tiene hoy el país en algunos elementos importantes sobre la abogacía en cuba. No obstante, resalta que esa es la voluntad de la dirección de la Organización y por ello se están tomando un grupo de acciones tendentes a pensar, a reflexionar sobre cuál sería el futuro de tan importante ejercicio profesional en el país. De igual modo manifiesta que existe consenso entre todos los compañeros que están dedicados a este análisis como también los miembros de la Organización en relación a la necesidad de mantener la abogacía colectiva en Cuba.

La abogacía colectiva se debe mantener no solo por su esencia de vocación por la justicia desde una perspectiva de compromiso social, sino también como un mecanismo de autoprotección. Un abogado de manera liberal o independiente carece de protección frente a un sistema jurídico, con independencia de lo que se pueda decir de este tipo de forma de ejercicio profesional generalmente practicada en otros países. El entrevistado para graficar tal aseveración formula las siguientes interrogantes: ¿qué sería de un abogado solo en Maisí si no contara con una abogacía estructurada como la que tenemos?, ¿de qué se pudiera valer en el acceso al constante movimiento de transformaciones que se operan hoy en el sistema jurídico?, ¿cómo pudiera tener un respaldo material y cómo pudiera tener también un respaldo en la actuación profesional? Sería bastante complejo, por lo cual los miembros de la Organización con ese sentido de autoprotección proponen la permanencia de la abogacía colectiva.

Sin embargo, como Fernández-Rubio, ahora se considera que lo que sí debe cambiar en primer lugar es el instrumento legal que norma esta actividad en el país. Se ha pensado que el Decreto-Ley 81 si bien se intitula "Del ejercicio de la abogacía y de la Organización Nacional de Bufetes Colectivos", no desarrolla a plenitud lo relativo al ejercicio de la abogacía. Situación que se considera necesaria porque existen otras formas de ejercitar la abogacía que no están necesariamente vinculadas a la Organización de Bufetes Colectivos y requieren ser normadas desde esta perspectiva, como son los servicios que prestan en este sentido las Consultorías Jurídicas o actuales EMPRESCONSUL.

Por otra parte, las propias estructuras de la Organización también se deben parecer un poco más a su tiempo, con independencia de que estructuralmente en término de concepto hayan cumplido su función. En este sentido, se debe avaluar si hay que dotar de mayor autonomía en la autogestión a las unidades de bufetes. ¿Qué roles deben jugar realmente las direcciones provinciales? Incluso se considera que la propia dirección nacional debe ser más operativa y menos cargada de trámites. Sin embargo, esto no significa la sustracción de la Organización de un espacio de Administración Pública que también le pone exigencias.

Por ahí transitan las dos grandes complejidades de la Organización que igualmente generan dos posiciones. Una, separar en instrumentos legales ambas normativas, es decir, el ejercicio de la abogacía y la Organización Colectiva de Bufetes. Y la otra posición que defiende 
que lo que debe existir en el país es una Ley del Ejercicio de la Abogacía que contenga el reconocimiento del ejercicio de la abogacía, defina quiénes son sus actores, cuál es su encargo social y, además de eso, que dé la protección a la libertad del ejercicio profesional.

Sobre tal debate existe bastante polémica, hasta la valoración incluso de que los actores que están surgiendo en la estructura socioeconómica del país deben o pueden contar con abogados propios. Por ejemplo, si el sector cooperativo puede tener un abogado propio, salido de las propias concepciones del ejercicio de la abogacía. Son temas que esa Ley vendría un poco a respaldar en la aceptación o el rechazo a ese pedido.

Otro elemento objeto de valoración sería la cuestión de la defensoría de oficio. ¿Quién se encargaría de la defensoría de oficio? ¿Sería una institución como existe en otros países, por ejemplo en Costa Rica, Argentina, México, donde hay cuerpos de defensoría de oficio o tendría que permanecer en la ONBC? Hay varias concepciones en aras de buscar la cuestión del perfeccionamiento. $\mathrm{Y}$ en cuanto al ejercicio de la abogacía, dotar a la Organización de más autonomía sin que eso constituya una negación al control social que en el orden reglamentario todos los Estados ejercen sobre las formas de organizaciones socioeconómicas en sus respectivos países. $Y$ en virtud de ello, hay otras cuestiones que van más a lo interno y están ya perfeccionándose y se ha de llegar al momento legislativo, como hacer un rediseño del sistema de superación profesional, de las estructuras de trabajo para la prestación de los servicios, es decir, si se tiene que continuar con los equipos de trabajo o pasar a otra forma de prestación de servicios.

La abogacía cubana tiene que perfeccionarse sin renunciar a los principios generales que la sustentan. En primer lugar porque se trata de una abogacía colectiva que respalda en el acceso de los ciudadanos a la justicia. Sería solo, coincidiendo con el entrevistado, en las grandes ciudades de este país donde se concentraría abogacía que propiciara el acceso a la justicia. En municipios como Maisí y Yateras no funcionaría la abogacía liberal. Eso no se puede perder de vista en un aniversario cerrado como el cincuenta. En consecuencia, una abogacía no colectiva como la cubana, tampoco posibilitaría en la actual medida la accesibilidad del ciudadano a la justicia, sobre todo por el sistema de precios que se establecería, alejado de todo compromiso social.

Hoy existen procesos en los cuales el sistema tarifado es expresión del compromiso de abogacía popular en el sentido de que un grupo de tarifas son prácticamente simbólicas, sin obviar que las consultas son gratuitas. En el mundo, por el contrario, ninguna consulta es gratuita. Un grupo de procesos no entrañan utilidad a los ingresos de la Organización; por ejemplo, las reclamaciones laborales son de las más baratos que tiene el sistema tarifado, y más los procesos relacionados con las cuestiones del Derecho de Familia. 
No obstante, en la actualidad se considera que este sistema de tarifas debe ser revisado buscando atemperarlas a la realidad de procesos en virtud de complejidades y clientes, sin que signifique la renuncia de su fundamento social. Pero no se puede obviar que hoy ante un delito de malversación de medio millón de pesos o más, el acusado solo paga por concepto del servicio del abogado 415,00 pesos e igual suma ante litigios civiles, donde se discuten bienes que superan los 30000 pesos, según el codificador actual.

Finalmente, el mayor reto continúa siendo la necesidad de que nuestros abogados, productos todos de un momento histórico de nuestra Revolución, personas humildes, mantengan esa humildad y quijotismo que es lo que en gran medida asegura la vinculación con el concepto de abogacía popular. Por tanto, no renunciar nunca al concepto de abogacía social que caracteriza a la ONBC.

\section{A modo de conclusiones}

El ejercicio de la abogacía tiene su génesis en Grecia y Roma y en Cuba fue importada con la colonización española. Aunque en algunos momentos se pudo ejercer sin la exigencia de una previa inscripción o registro, ciertamente primó el carácter obligatorio de la organización e integración en los Colegios de Abogados para el ejercicio de la profesión.

En el transcurso de la historia también la figura del abogado ha generado sentimientos contrapuestos: amistad y animadversión, admiración y desprecio cuyo maniqueísmo tiene su fundamento en las sociedades burguesas en las que para el abogado la meta era los ingresos que percibiría; pero con el triunfo revolucionario y la construcción del socialismo en Cuba y con este la colectivización de los servicios de asistencia jurídica a las personas jurídicas y naturales, no solo se fortalece el derecho de acceso a la justicia sino que se transforma aquella realidad y la abogacía se sustenta en un concepto popular.

La ONBC tiene treinta años, mientras que la abogacía colectiva en Cuba ya alcanza los cincuenta. Lo que invita a repensar el futuro de la abogacía en el país en una nueva etapa en la que los cambios que se producen en la sociedad imponen nuevos y complejos retos. Todo ello sin renunciar al modelo de abogacía popular y sus principios.

La sociedad cubana actual como parte de las sociedades modernas y en el marco de la actualización de su modelo económico impone nuevos retos al ejercicio de la abogacía. El abogado debe enfrentar hoy la tramitación de asuntos de mayor grado de complejidad asociados a las más diversas ramas del Derecho demandando de la Organización Nacional de Bufetes Colectivos:

- Una constante superación de sus miembros.

- El fortalecimiento de los mecanismos de control de carácter técnico y de la ética. 
- La revisión y perfeccionamiento de la actividad de estimulación a sus miembros.

- Revisión del sistema de tarifas actualmente establecidas en aras de que se corresponda con la nueva realidad, sin que ello vaya en detrimento del principio de garantizar el acceso a la justicia.

- La revisión y perfeccionamiento del instrumento legal que norma su ejercicio.

\section{LEGISLACIÓN}

- Ley de Enjuiciamiento Criminal (1967): [anotada y concordada por E. G. Merino Brito], Instituto Cubano del Libro, La Habana.

- Ley de Enjuiciamiento Criminal (1992): Ed. Civitas, Madrid.

- Ley de Procedimiento Penal, Ley no. 1251 de 25 de junio de 1973. Publicada en la Gaceta Oficial de la República de Cuba, edición ordinaria No. 14, de 26 de junio de 1973.

- Ley No. 1250, Ley de Organización del Sistema Judicial de 23 de junio de 1973 (1974): 2da ed., Ed. Orbe, La Habana.

- Ley de Procedimiento Penal, Ley no. 5 de 13 de agosto de 1977. Publicada en la Gaceta Oficial de la República de Cuba, edición ordinaria, No. 33 de 18 de agosto de 1977.

- Ley de Procedimiento Penal, Ley No. 5 de 13 de agosto de 1977 (2012): [anotada y concordada con las Disposiciones del CGTSP, por D. Rivero García], 2da. ed., Ediciones ONBC, La Habana.

- Ley de Organización del Sistema Judicial, Ley No. 250. Publicada en la Gaceta Oficial de la República de Cuba, edición ordinaria, No. 13, de 23 de junio de 1973.

- Ley de Procedimiento Penal Militar, Ley No. 6 de 8 de agosto de 1977. Publicada en la Gaceta Oficial de la República de Cuba, edición ordinaria, No. 33, de 18 de agosto de 1977.

- Ley de Organización del Sistema Judicial, Ley No. 4, de 10 de agosto de 1977. Publicada en la Gaceta Oficial de la República de Cuba, edición ordinaria, No. 36, de 25 de agosto de 1977.

- Ley Orgánica del Poder Judicial, Decreto-Ley No. 127 de 27 de enero de 1909, Impr., y Papelería de Rambla y Bouza, La Habana.

- Ley de Enjuiciamiento Criminal (1883): edición concordada y anotada extensamente bajo la dirección de don Emilio Reus, t. I., Impr. de la Revista de Legislación, Madrid. 
- Decreto-Ley 81 de 8 de junio de 1984. Disponible en: Divulgación del Ministerio de Justicia. Impreso en el MINJUS, febrero, 1988.

- Reglamento 18 de diciembre de 1984. Disponible en: Divulgación del Ministerio de Justicia. Impreso en el MINJUS, febrero, 1988.

- Acuerdo 895 de la ONBC de 28 de junio de 2012.

\section{REFERENCIAS}

- Cagigas Rodríguez, Alida y Pavel Peterssen Padrón. Aproximación a la responsabilidad de los abogados en el ejercicio de la profesión y sus mecanismos de protección legal. Disponible en: CD del Congreso Abogacía, 2014.

- Fontán Balestra, Carlos. Derecho Penal. Introducción y Parte General. 1998.

- Goite Pierre, Maya y Juan Mendoza Díaz. "Los sujetos de la relación jurídico-procesal”. En Temas para el estudio del Derecho Procesal Penal. Primera Parte. La Habana: Editorial Félix Varela, 2002.

- Llorente. Los Bufetes Colectivos en la historia. Documento inédito. 2014.

- Ossorio, Ángel. El ángel de la toga. Buenos Aires; Argentina: Losada, 1942.

- Prieto Morales, Aldo. Derecho Procesal Penal. Primera Parte. 1976. 